\title{
The effect of root pruning on the arbuscular mycorrhizal symbiosis in grapevine rootstocks
}

\author{
Taylor Holland ${ }^{1}$, Pat Bowen ${ }^{2}$, Vasilis Kokkoris ${ }^{1}$, Andrew Richards' ${ }^{1}$, Daniel Rosa ${ }^{1}$ and Miranda Hart ${ }^{1 *}$ (D)
}

\begin{abstract}
Background: Arbuscular mycorrhizal fungi provide benefits to plants, especially under stressful growing conditions. These symbiotic fungi can be applied as biofertilizers prior to transplant in order to increase establishment success in the field. Roots are often trimmed at the time of transplant to reduce the probability of J-rooting, the upward orientation of roots within a planting hole which can lead to root death and disease. The effect of root trimming on the mycorrhizal symbiosis is unknown. It is possible that trimming may remove the active mycelium, nullifying the effect of inoculation. We conducted a greenhouse study to test the effect of root trimming on the mycorrhizal symbiosis in grapevine.

Results: The mycorrhizal symbiosis persisted after root trimming. Trimming reduced the abundance of AM fungi in older roots. The fungi were able to recolonize the new roots in trimmed vines, and these roots had more arbuscules compared to older roots, which had mostly vesicles. Trimmed vines had lower shoot, but not root, biomass.

Conclusions: The mycorrhizal symbiosis persisted in the roots, despite trimming, likely due to fungal structures in older, untrimmed roots serving as propagules. We conclude that inoculation with AM fungi prior to field transplant is robust to root trimming, at least for the isolate examined in this study.
\end{abstract}

Keywords: Arbuscular mycorrhizal fungi, Root, Pruning, Transplant, Grapevine, J-root

\section{Background}

Grapes are an important global crop grown for both wine and fruit production. Perhaps the most vulnerable part of the growing cycle is transplant from nursery to vineyard. When plants are transitioned from the nursery to the field, they are exposed to unfamiliar abiotic conditions and soil pathogens, often acting as stressful factors affecting vine growth [1-4]. An important research goal is to find sustainable methods to improve vine establishment during transplant into the field.

One cultural method used to improve vine establishment during transplant is trimming roots. This practice reduces the incidence of roots growing upward because of limited space in the planting hole, resulting in a "J-rooting" pattern. J-rooting can lead to root death and has been associated with the incidence of root and

\footnotetext{
*Correspondence: Miranda.hart@ubc.ca

${ }^{1}$ UBC Okanagan, 3333 University Way, Kelowna, BC V1V 1V7, Canada

Full list of author information is available at the end of the article
}

trunk disease [4]. To avoid J-rooting, roots are aggressively pruned before planting. Such trimming practices are associated with increased proliferation and growth rate of roots [5].

Although pruning reduces the incidence and severity of J-rooting, it is not without drawbacks. Pruning wounds root tissues, making them vulnerable to infection $[6,7]$. In addition, trimming reduces the vigor of young vines, likely due to a smaller root system and subsequent reduced water uptake and transpiration $[8,9]$.

One consequence of root pruning rarely considered is the impact it has on beneficial root endophytes, such as arbuscular mycorrhizal (AM) fungi. AM fungi are obligate root symbionts that associate with the roots of most plants [10]. They grow from root cortical cells into the surrounding soil, greatly increasing resource access and uptake by plants [11]. Soil resources are exchanged for plant-derived carbon within specialized fungal structures called arbuscules, which are highly branched hypha enveloped by a root cell. The AM hyphal 
network significantly increases the uptake of resources and improves stress tolerance. For instance, AM fungi help maintain vine growth in saline soils [2], reduce the impact of pathogens [12] and improve plant water status and water-use efficiency [13].

How root pruning affects the mycorrhizal symbiosis is not known. It is likely that the distribution of AM fungal structures through the root system will influence the impact of root pruning on the symbiosis. For instance, arbuscules are often found in young absorptive roots near the growing root tips, whereas vesicles and spores are more abundant in older roots [14-16]. Depending on the severity of root pruning, the entire mycelium may be eliminated. Alternatively, trimming only the young growing roots may remove the hyphae in the root tips, leaving only fungal storage structures (i.e., vesicles) within the older root system-perhaps serving as an inoculum source for new roots. If the mycorrhiza cannot reestablish, the young grapevines will be at a significant disadvantage due to the reduced root area and the loss of symbiotic benefits. Thus, trimming, while useful to prevent J-rooting, may inhibit a functional AM symbiosis that could be critical for the survival of the grapevine during the transition from nursery to field.

The goal of this experiment was to determine how root trimming practices affect the mycorrhizal symbiosis. We hypothesized that root trimming would either reduce or eliminate the active mycorrhiza from grapevine roots.

\section{Methods}

\section{Rootstock preparation and treatment}

Rootstock canes were collected from the rootstock collection block at the Summerland Research and Development Centre, Agriculture and Agri-Food Canada, Summerland BC, in May of 2017. Twelve canes of similar diameter were collected for each of four rootstocks (5C, 3309C, 101-14Mgt, and Ramsey). The canes were soaked in $10 \%$ bleach for one minute and then rinsed with reverse osmosis (RO)-treated water. The basal end was cut within $5 \mathrm{~mm}$ below a node leaving three or four viable buds above the cut. The basal ends of the canes were soaked in liquid rooting hormone, indole-3-butyric acid (5000 ppm), for $4 \mathrm{~min}$ and then allowed to dry before planting in a rooting box filled with damp perlite. The rooting box was placed in a cooler at $4{ }^{\circ} \mathrm{C}$ to delay bud break of apical buds, while a heating pad underneath maintained a root zone temperature of $22^{\circ} \mathrm{C}$ to promote rooting.

Once roots had established, the rooted canes were transplanted into $4 \mathrm{~L}$ pots, in a 1:2 mixture of Turface:Sand. Each vine was inoculated with $15 \mathrm{~mL}$ of AgTiv ${ }^{\circledR}$ Specialty Crops wettable powder (Rhizoglomus irregularis at 20,000 propagules per g) which was distributed over the roots, covering them prior to filling the pot with media. These were grown in the Summerland Research and Development Centre greenhouse for 1 year, provided supplemental lighting to ensure a 16-h photoperiod, watered two or three times a week to saturation, and fertigated bi-weekly with a solution of $15 \mathrm{~mL}$ of Miracle-gro (24-8-16) dissolved in $6 \mathrm{~L}$ of water. After 1 year the plant roots were checked for mycorrhizal colonization using staining and microscopy, explained in the following section.

Having confirmed colonization, the root trimming treatment was applied to half of the plants in June of 2018 at the University of British Columbia Okanagan campus, Kelowna BC, Canada. Before treatment, all the vines were removed from their pots and rinsed of planting medium. Six vines of each rootstock had the actively growing lower zone of the root mass removed leaving only $<10 \mathrm{~cm}$ of root tissue and the remaining six vines were left untrimmed. All plants were repotted into 8-L pots with new sterile medium composed of sand. All vines were arranged in a completely randomized design on a greenhouse bench.

The vines were grown for 4 months to allow new root growth. During this time, plants were irrigated via drip emitters, providing $300 \mathrm{~mL}$ of water every day. Plants were grown with supplemental lighting to ensure they received a 16-h photoperiod. At the end of 4 months, aboveground biomass was harvested, weighed, dried in an oven $\left(50{ }^{\circ} \mathrm{C}\right)$ for $48 \mathrm{~h}$, and re-weighed. Roots were removed from pots and washed free of any sand, and two 5-g samples were taken from the root mass and stored at $4{ }^{\circ} \mathrm{C}$ for visual analysis and molecular quantification. One root sample was taken from the actively growing roots within the bottom $5 \mathrm{~cm}$ of the roots. The other was taken from the older roots, no longer actively growing, within $5 \mathrm{~cm}$ of the stem base. The remaining roots were dried $50{ }^{\circ} \mathrm{C}$ in an oven for $48 \mathrm{~h}$ and weighed.

\section{Staining and visual quantification}

The sampled roots were stained and visually inspected for the abundance of arbuscular mycorrhizal structures. A staining protocol was used, modified from Vierheilig et al. [17]. Roots were soaked in $10 \% \mathrm{KOH}$, at $90^{\circ} \mathrm{C}$, for $3 \mathrm{~h}$, followed by soaking overnight in room-temperature $10 \% \mathrm{KOH}$. Roots were then rinsed with $\mathrm{RO}$ water and stained for $15 \mathrm{~min}$ in a $90{ }^{\circ} \mathrm{C}, 5 \%$ solution of Sheaffer black ink:5\% vinegar. Last, the roots were de-stained for $20 \mathrm{~min}$ in $0.01 \%$ vinegar:RO water. The roots were mounted in polyvinyl-lacto-glycerol (PVLG) and baked at $60{ }^{\circ} \mathrm{C}$ until the media hardened, then viewed at $200 \times$ magnification to quantify the abundance of mycorrhizal structures (vesicles, arbuscules and AM fungal presence/ absence) using the method of McGonigle et al. [18]. 
DNA extraction and molecular AMF quantification

To perform molecular quantification of the AM fungal isolate, DNA was first extracted from the two 0.1-g subsamples of roots per plant (one from the upper root-system sample, one from the lower active root zone isolated during harvest), according to the manufacturer's protocol (MPBio FastDNA ${ }^{\mathrm{TM}}$ SPIN kit (MP Biomedicals LLC). This was followed by digital droplet (dd) PCR, which quantifies the number of a specific gene segment within a sample.

To quantify AM fungi, we targeted a segment of the mitochondrial DNA (mtDNA) specific to the commercial isolate using a probe-based reaction (197198F 5'-AGCAAATCTAAGTTCCTCAGAG-3' [19]; Reverse 5'-ACTTCTATGGCTTTGTACAGG-3'; and probe $5^{\prime}$ - FAM/CCC ACC AGG/ZEN/GCA GAT TAATCT TCCTT/3IABKFQ-3' [20]. Each ddPCR contained: $10 \mu \mathrm{L}$ of $1 \times$ ddPCR SensiMix (supermix for probes by Bio-Rad Inc), $1 \mu \mathrm{L}$ of $20 \times$ primer-probe mix (Integrated DNA Technologies) (500 $\mathrm{nM}$ primers and $250 \mathrm{nM}$ probe in final reaction), $2 \mu \mathrm{L}$ of undiluted root DNA and $7 \mu \mathrm{L}$ of DNase-free water, for a total volume of $20 \mu \mathrm{L}$. The total reaction volume in addition with $70 \mu \mathrm{L}$ of Bio-Rad Droplet Generator Oil for Probes was used to produce $40 \mu \mathrm{L}$ of droplets, via the Bio-Rad QX100 Droplet Generator. Thermal cycling conditions were $95{ }^{\circ} \mathrm{C}$ for $10 \mathrm{~min}$, followed by 40 cycles of $94{ }^{\circ} \mathrm{C}$ for $30 \mathrm{~s}$ and $59{ }^{\circ} \mathrm{C}$ for $30 \mathrm{~s}$, followed by a single step at $98{ }^{\circ} \mathrm{C}$ for $10 \mathrm{~min}$; the ramp rate was increased by $2{ }^{\circ} \mathrm{C} / \mathrm{s}$.

Droplet analysis was carried out on the BioRad QX100 and raw data were collected using Quantalife software (Version 1.7.4.0917, Bio-Rad Laboratories Inc.). For each run, we included three non-template controls (NTC) containing no DNA and three negative controls which contained no commercial inoculum DNA. The former is to eliminate the possibility of contamination and the latter to determine the fluorescence amplitude threshold.

\section{Statistical analysis}

A linear mixed model was used, to compare the abundance of mtDNA (ddPCR) and mycorrhizal structures. The lme4 package was used with the formula lmer(Response $\sim$ Treatment $*$ Region $+(1 \quad$ Rootstock $))$, where Treatment and Region are main effects and Rootstock is a random factor. For plant responses (dry root mass and dry aboveground mass), a similar model was used with the formula lmer(Response $\sim$ Treatment $+(1$ | Rootstock)), where Treatment is main effect and Rootstock is a random factor. Welch's Two-Sample $t$-test was used in some instances to compare groups after significant interactions were detected between treatments.

\section{Results}

Root trimming effects on AM fungi and rootstocks

Trimming did not affect mtDNA concentration within root systems (Table 1) but an interaction was found between trimming and region of root system sampled $(p=0.035)$, indicating that trimming reduced AM fungal mDNA abundance in the older root zone only $(t=2.97$, $p=0.006$ ) (Fig. 1). The abundance of mycorrhizal structures was not influenced by trimming (Table 1). Vines had lower aboveground biomass (approximately 12\%) when roots were trimmed $(p=0.039)$, but root biomass was not affected by the trimming treatment $(p=0.176)$ (Table 1). There was no interaction between rootstock identity and root trimming in regard to AM fungal abundance or plant biomass.

\section{Old versus new roots}

There was no difference in fungal mtDNA abundance between older and newer roots $(p=0.204)$ (Table 1$)$. There were, however, more arbuscules in the newer roots $(p=0.004)$, but vesicle abundance $(p<0.001)$ and total colonization $(p=0.004)$ were higher in the old roots (Fig. 2).

\section{Discussion}

Contradictory to our hypothesis, root trimming did not reduce the abundance of AM fungi in new roots. However, root trimming decreased fungal abundance within the old roots.

The impact of root trimming on the mycorrhizal symbiosis We predicted that a trimmed root system would have less AM fungal abundance due to the removal of mycorrhizal resources. Instead, the AM fungi in this study tolerated the trimming treatment, with both new and old roots exhibiting high levels of AM fungal mtDNA and colonization 15 weeks post-trimming. In general, root damage has been found to reduce fungal abundance. For instance, disrupting roots via soil tillage has been shown to significantly decrease the abundance and slow the development of mycorrhizae [21-23]. Similarly, early root herbivory can decrease the ability of mycorrhiza to form [24], but herbivory effects on AM fungi will vary on a per-study basis [25]. In our study, because only the youngest roots are removed by root trimming, it is likely that the mycelium in older roots served as inoculum for new root growth.

Whether or not this resistance to disturbance is true for all AM fungi remains to be seen. Due to physiological differences among AM fungal species, such as propagule production $[26,27]$, different AM fungi will vary in their response to disturbance such as root trimming or disruption [28]. For instance, tillage in agricultural studies has led to shifts in AM fungal community composition, 
Table 1 Linear mixed-effect model results for different fungal and plant responses measured after vines were either trimmed or not, and from different areas of the root system

\begin{tabular}{llll}
\hline Factor & Effect & & \\
\cline { 2 - 4 } & $\begin{array}{l}\text { Trimming } \\
\text { treatment }\end{array}$ & $\begin{array}{l}\text { Upper vs. } \\
\text { lower roots }\end{array}$ & Interaction \\
\hline mtDNA concentration & 0.222 & 0.204 & 0.036 \\
Arbuscules & 0.765 & 0.004 & 0.979 \\
Vesicles & 0.302 & $<0.001$ & 0.997 \\
Total colonization & 0.629 & 0.004 & 0.721 \\
Aboveground mass & 0.039 & $\mathrm{~N} / \mathrm{A}$ & $\mathrm{N} / \mathrm{A}$ \\
Root mass & 0.176 & $\mathrm{~N} / \mathrm{A}$ & $\mathrm{N} / \mathrm{A}$ \\
\hline
\end{tabular}

$\mathrm{N} / \mathrm{A}$ refers to comparisons that were not applicable

The Imer package (from the Ime4 package) was used to determine differences in response due to a trimming treatment and between root areas (for mycorrhizal measures), including their interaction. Rootstock included as a random factor, not shown due to lack of interaction. Italicized values indicate significance at $p=0.05$

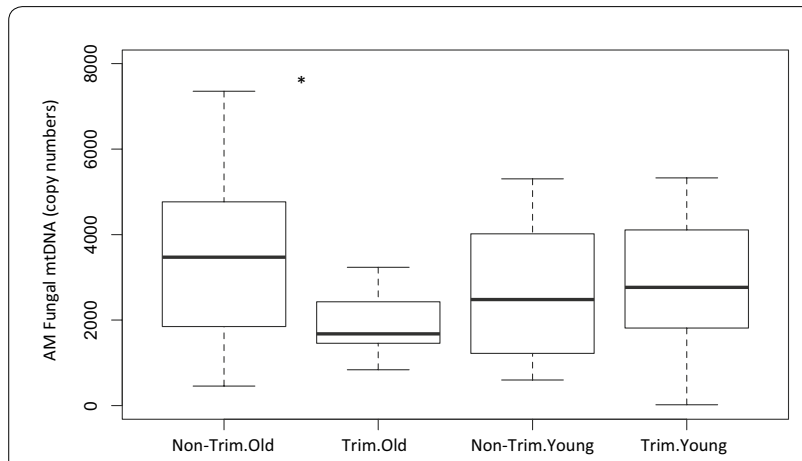

Fig. 1 The quantity of AM fungal mitochondrial LSU gene copies in root systems that were trimmed (trim) or not (non-trim), and from either the old and young roots. An interaction was detected between trimming and root location $(p=0.033)$. The asterisk indicates a difference in AM fungal mtDNA between the non-trimmed old and trimmed old roots, detected using a Welch Two-Sample $t$-test $(t=2.97, p=0.006)$

resulting in decreased diversity [21, 28]. Species that grow rapidly or produce more vesicles and spores are likely to become the dominant species in these situations [29-31]. Trimming represents a specialized form of disturbance compared to tillage. Because the mycelium is only retained within the roots-and not in the soil-only fungi capable of regrowth from root colonization may tolerate root trimming. Taxa that rely on spores or soil hyphae to initiate new infection units (i.e., Gigasporaceae and Scutellospora [27]) may be unable to regrow following trimming. Similarly, the vines will be subjected to a resident fungal community in the field, unlike our system where they were trimmed and potted into sterile media.

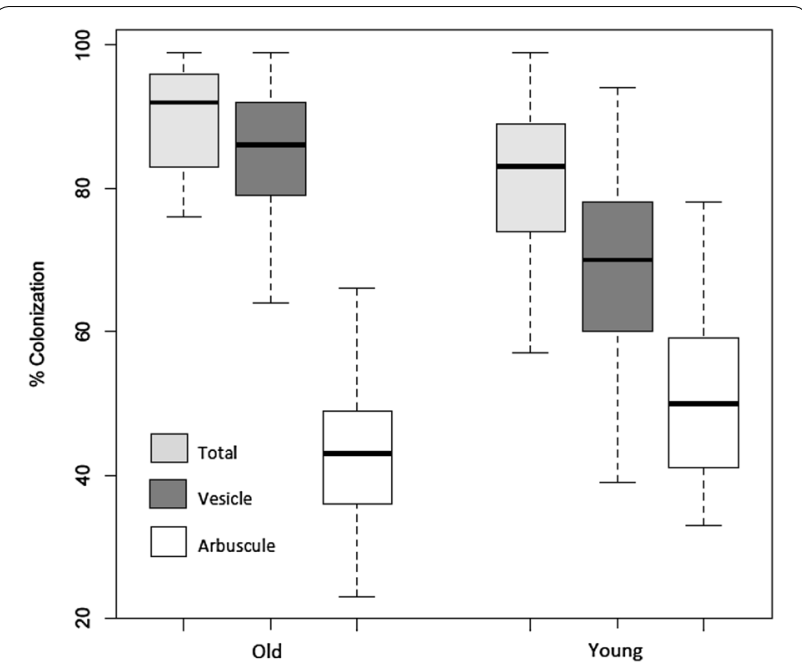

Fig. 2 Percent colonization of vine roots collected from the 'old'and 'young' roots of 48 rootstocks. The quantity of all three structures differed between zones (total, $p=0.004$; vesicles, $p<0.001$; arbuscules, $p=0.004$ )

It may be that the residual mycelium in trimmed roots may not be competitive with resident fungi, and may fail to persist in field conditions. This remains to be tested.

Trimming lowered the abundance of AM fungi within the older roots. Our measure of fungal abundance, mtDNA concentration, is also associated with metabolic activity. This difference in mtDNA, together with the lack of difference in colonization (arbuscules, vesicles and total), indicates less mycorrhizal activity within the older roots of trimmed root systems. Why does trimming the root system lower the mycorrhizal activity within the older roots? It could be that trimming roots causes a greater need for the regeneration of new roots and mycorrhizal symbiosis. Further, it has been shown that plants with a loss of root area may depend more upon the mycorrhizal symbiosis [32, 33]. If trimming causes increased root production and a greater dependency on the mycorrhizal symbiosis, more mycorrhizal development would likely be concentrated in newer roots, pulling resources and activity away from the older root system potentially resulting in the increased mtDNA in the lower, younger roots. While this is speculative, it indicates that a better understanding is on how root disturbance, such as root damage, can influence both plant carbon and biomass allocation, and the subsequent effects on mycorrhizal development.

\section{Distribution of AM fungal structures between old and new roots}

Older roots harbored more vesicles and overall colonization of AM functional structures than newer roots, which had more arbuscules. Similar results have been found 
previously in grapevine [16] and other plant species [34]. The lower roots are smaller, unbranched, and responsible for accessing and absorbing nutrients and water [35]. Arbuscules are short-lived structures with highest abundance in young roots, declining with age $[14,34]$. Therefore, in the present study, it was expected that arbuscules would be more abundant in these lower roots, allowing for more nutrient exchange in this zone, and that arbuscular degradation would occur in older roots. The abundance of vesicles in the older roots suggests that they were primarily a source of carbon for the fungus, since these structures are important in providing resources to new mycorrhizal growth $[27,36]$. It is likely that the vesicle and hypha contained within older roots served as a source of inoculum for the trimmed roots.

\section{Root trimming and vine growth}

The reduction of vine shoot biomass due to root trimming has been seen in previous studies [37, 38]. This response may be from a combination of nutrient limitations due to reduced root biomass, plus an allocation of plant resources to root growth [5]. This initial loss of aboveground biomass may reduce the first years' growth after transplant, but whether this has long-term effects on vine establishment, such as years until fruit set, is unknown.

That we observed no difference in root biomass between trimmed and untrimmed root systems provides evidence that root trimming increased the allocation of biomass toward root development and regeneration, maintaining their shoot:root ratio. This redistribution of biomass in response to root trimming has been previously observed $[39,40]$. This increase in root production is important to growers as it indicates that the root system will regenerate after root pruning, while also being provided the benefits of avoiding J-rooting. While aboveground biomass production may be reduced, the allocation toward root may be more beneficial in the establishment of young vines, an area that needs to be tested further in the field.

\section{Conclusion}

This study indicates that root trimming does not compromise the AM symbiosis under the conditions of our experiment. AM fungi persisted in the roots, regardless of root trimming. It is probable that older roots with an abundance of vesicles served as a source of inoculum for new roots post-trimming. It is also likely that after root trimming, more resources are allocated to the root system to recover lost biomass, and mycorrhizal fungi are more active in the lower roots of a trimmed root system. Whether these findings would be similar for all species and isolates of AM fungi remains to be seen. The high vesicle colonization and re-colonization of newly growing roots observed in this study indicate that the commercial isolate used in this study may be a suitable choice for precolonizing vines. However, it will be important for future research to test the role of resident fungi within vineyard soils in affecting the persistence of the pre-inoculated fungus.

\section{Abbreviations \\ AM: arbuscular mycorrhiza; ddPCR: digital droplet polymerase chain reaction; mtDNA: mitochondrial DNA; NTC: non-template control. \\ Acknowledgements \\ A thank you must be extended to Sarah Bird for helping with the setup and maintenance of the experiment and Cameron Egan for advice with analysis of data.}

\section{Authors' contributions}

Design by $\mathrm{TH}, \mathrm{PB}$ and $\mathrm{MH}$; setup and maintenance by $\mathrm{TH}$ and $\mathrm{DR}$; harvest and lab work by TH, VK, DR and AR; analysis by TH and VK; written by TH and MH. All authors read and approved the final manuscript.

\section{Funding}

Funding was provided by NSERC (TH) and Agriculture and Agri-Food Canada Growing Forward 3 (MM) and BC Wine Grape Council and Agriculture and Agri-Food Canada, Agri-Science Project (PB).

\section{Availability of data and materials}

The datasets used and/or analyzed during the current study are available from the corresponding author on reasonable request.

\section{Ethics approval and consent to participate}

Not applicable.

\section{Consent for publication}

Not applicable.

\section{Competing interests}

The authors declare that they have no competing interests.

\section{Author details}

${ }^{1}$ UBC Okanagan, 3333 University Way, Kelowna, BC V1V 1V7, Canada. ${ }^{2}$ AAFCSuRDC, 4200 Hwy 975, Summerland, BC VOH 1Z0, Canada.

Received: 23 May 2019 Accepted: 9 July 2019

Published online: 05 November 2019

\section{References}

1. Bavaresco L, Poni S. Effect of calcareous soil on photosynthesis rate, mineral nutrition, and source-sink ratio of table grape. J Plant Nutr. 2003;28:2123-35

2. Belew TA, Mokashi MN, Getachew Y, Patil CP. Effects of salinity and mycorrhizal inoculation (Glomus fasciculatum) on growth responses of grape rootstocks (Vitis spp.). S Afr J Enol Vitic. 2010;31:82-8.

3. Nogales A, Aguirreolea J, Maria ES, Camprubi A. Response of mycorrhizal grapevine to Armillaria mellea inoculation: disease development and polyamines. Plant Soil. 2009;317:177-87.

4. Urbez-Torres JR, Haag P, Bowen PA, O'Gorman DT. Grapevine trunk diseases in British Columbia: incidence and characterization of the fungal pathogens associated with Black Foot Disease of grapevine. Plant Dis. 2014;98:456-68.

5. Geisler D, Ferree DC. Response of plants to root pruning. Hortic Rev. 1984;6:155-88. 
6. Agusti-Brisach C, Armengol J. Black-foot disease of grapevine: an update on taxonomy, epidemiology and management strategies. Phytopathol Meiterr. 2013;52:245-61.

7. Gramaje D, Armengol J. Fungal trunk pathogens in the grapevine propagation process: potential inoculum sources, detection, identification, and management strategies. Plant Dis. 2011;95:1040-55.

8. Ferree DC, Scurlock DM, Schmid JC. Root pruning reduces photosynthesis, transpiration, growth and fruiting of container-grown French-American hybrid grapevines. HortScience. 1999;34:1064-7.

9. Poni S, Tagliavini M, Neri D, Scudellari D, Toselli M. Influence of root pruning and water stress on growth and physiological factors of potted apple, grape, peach and pear trees. Sci Hortic. 1992;52:223-36.

10. Brundrett M. Mycorrhizal associations and other means of nutrition of vascular plants: understanding the global diversity of host plants by resolving conflicting information and developing reliable means of diagnosis. Plant Soil. 2009;320:37-77.

11. Smith SE, Read DJ. Mycorrhizal symbiosis. Third edn. London: Academic Press; 2008.

12. Petit $E$, Gubler WD. Influence of Glomus intraradices on black foot disease caused by Cylindrocarpon macrodidyum on Vitis rupestris under controlled conditions. Plant Dis. 2006;90:1481-4.

13. Nicolás E, Maestre-Valero JF, Alarcón JJ, Pedrero F, Vicentre-Sánchez J, Bernabé A, Gómez-Montiel J, Hernández JA, Fernández F. Effectiveness and persistence of arbuscular mycorrhizal fungi on the physiology, nutrient uptake and yield of Crimson seedless grapevine. J Agric Sci. 2015. https://doi.org/10.1017/s002185961400080x.

14. Barker SJ, Tagu D, Delp G. Regulation of root and fungal morphogenesis in mycorrhizal symbiosis. Plant Physiol. 1998;116:1201-7.

15. Resendes ML, Bryla DR, Eissenstat DM. Early events in the life of apple roots: variation in root growth rate is linked to mycorrhizal and nonmycorrhizal fungal colonization. Plant Soil. 2008:313:175-86.

16. Vukicevich E, Lowery DT, Eissenstat D, Hart M. Changes in arbuscular mycorrhizal fungi between young and old Vitis roots. Symbiosis. 2019. https://doi.org/10.1007/s13199-019-00598-3.

17. Vierheilig H, Coughlan AP, Wyss U, Piche Y. Ink and vinegar, a simple staining technique for arbuscular-mycorrhizal fungi. Appl Environ Microbiol. 1998;64:5004-7.

18. McGonigle TP, Miller MH, Evans DG, Fairchild GL, Swan JA. A new method which gives an objective measure of colonization of roots by vesicular-arbuscular mycorrhizal fungi. New Phytol. 1990;115:495-501.

19. Providencia IE, Nadimi M, Beaudet D, Morales GR, Hijri M. Detection of a transient mitochondrial DNA heteroplasmy in the progeny of crossed genetically divergent isolates of arbuscular mycorrhizal fungi. New Phtyol. 2013;200:211-21.

20. Kokkoris V, Li Y, Hamel C, Hanson K, Hart M. Site specificity in establishment of a commercial arbuscular mycorrhizal fungal inoculant. Sci Tot Environ. 2019;660:1135-43

21. Bowles TM, Jackson LE, Loeher M, Cavagnaro TR. Ecological intensification and arbuscular mycorrhizas: a meta-analysis of tillage and cover crop effects. J Appl Ecol. 2017;54:1785-93.

22. Lekberg Y, Koide RT. Is plant performance limited by abundance of arbuscular mycorrhizal fungi? A meta-analysis of studies published between 1988 and 2003. New Phytol. 2005:2005(168):189-204.

23. McGonigle TP, Miller MH. Mycorrhizal development and phosphorus absorption in maize under conventional and reduced tillage. Soil Sci Soc Am J. 1993;57:1002-6.
24. Bennett AE, Macrae AM, Moore BD, Caul S, Johnson SN. Early root herbivory impairs arbuscular mycorrhizal fungal colonization and shifts defense allocation in establishing Plantago lanceolata. PLoS ONE. 2013;8(6):e66053.

25. Johnson SN, Rasmann S. Root-feeding insects and their interactions with organisms in the rhizosphere. Annu Rev Entomol. 2015;60:517-35.

26. Hart MM, Reader RJ. Taxonomic basis for variation in the colonization strategy of arbuscular mycorrhizal fungi. New Phytol. 2002;135:335-44.

27. Klironomos JN, Hart MM. Colonization of roots by arbuscular mycorrhizal fungi using different sources of inoculum. Mycorrhiza. 2002;12:181-4.

28. Kabir Z. Tillage or no-tillage: impact on mycorrhizae. Can J Plant Sci. 2005:85:23-9.

29. Douds DD, Glaves L, Janke RR. Effects of tillage and farming system upon populations and distribution of vesicular-arbuscular mycorrhizal fungi. Agric Ecosyst Environ. 1995:52:111-8.

30. Jansa J, Mozafar A, Kuh G, Anken T, Ruh R, Sanders IR, Frossard E. Soil tillage affects the community structure of mycorrhizal fungi in maize roots. Ecol Appl. 2003;13:1164-76.

31. Johnson NC, Pfleger FL. Vesicular-arbuscular mycorrhizae and cultural stress. In: Bethlenfalvay GJ, Linderman RG, editors. Mycorrhizae in sustainable agriculture. Madison: ASA; 1992. p. 71-100.

32. Graham JH, Duncan LW, Eissenstat DM. Carbohydrate allocation patterns in citrus genotypes as affected by phosphorus nutrition, mycorrhizal colonization and mycorrhizal dependency. New Phytol. 1997; 135:335-43.

33. Tawaraya K. Arbuscular mycorrhizal dependency of different plant species and cultivars. Soil Sci Plant Nutr. 2003;49:655-68

34. Rosewarne GM, Barker SJ, Smith SE. Production of near-synchronous fungal colonization in tomato for developmental and molecular analyses of mycorrhiza. Mycol Res. 1997;101:966-70.

35. Eissenstat DM, Wells CE, Yanai RD, Whitbeck JL. Building root in a changing environment: implications for root longevity. New Phytol. 2000; 147:33-42.

36. Brundrett M. Mycorrhizas in natural ecosystems. Adv Ecol Res. 1991;21:171-313.

37. Dong SF, Cheng LL, Scagel CF, Fuchigami LH. Root damage affects nitrogen uptake and growth of young Fuji/M.26 apple trees. J Hortic Sci Biotechnol. 2003;78:410-5.

38. Hipps NA, Higgs $\mathrm{KH}$, Collard LG. Effects of root wrenching on the growth and water relations of Prunus avium and Castanea sativa seedlings in nursery beds and after outplanting. Can J For Res. 1996;29:696-704.

39. Poorter H, Niklas KJ, Reich PB, Oleksyn J, Poot P, Mommer L. Biomass allocation to leaves, stems and roots: meta-analysis of interspecific variation and environmental control. New Phytol. 2012;193:30-50.

40. Poorter $\mathrm{H}$, Nagel $\mathrm{O}$. The role of biomass allocation in the growth response of plants to differential levels of light, $\mathrm{CO}_{2}$, nutrients and water: a quantitative review. Aust J Plant Physiol. 2000;27:1191.

\section{Publisher's Note}

Springer Nature remains neutral with regard to jurisdictional claims in published maps and institutional affiliations.

\section{Submit your manuscript to a SpringerOpen ${ }^{\odot}$ journal and benefit from:}

- Convenient online submission

- Rigorous peer review

- Open access: articles freely available online

- High visibility within the field

Retaining the copyright to your article

Submit your next manuscript at springeropen.com 